\title{
Article \\ CFD Simulation of Solid Suspension for a Liquid-Solid Industrial Stirred Reactor
}

\author{
Adrian Stuparu *(D), Romeo Susan-Resiga (D) and Alin Bosioc \\ MMUT, Faculty of Mechanical Engineering, Politehnica University Timisoara, 300006 Timisoara, Romania; \\ romeo.resiga@upt.ro (R.S.-R.); alin.bosioc@upt.ro (A.B.) \\ * Correspondence: adrian.stuparu@upt.ro
}

check for updates

Citation: Stuparu, A.; Susan-Resiga, R.; Bosioc, A. CFD Simulation of Solid Suspension for a Liquid-Solid Industrial Stirred Reactor. Appl. Sci. 2021, 11, 5705. https://doi.org/ 10.3390/app11125705

Academic Editors: Francesca Scargiali and Hoyas Calvo Sergio

Received: 28 April 2021

Accepted: 15 June 2021

Published: 19 June 2021

Publisher's Note: MDPI stays neutral with regard to jurisdictional claims in published maps and institutional affiliations.

Copyright: (c) 2021 by the authors. Licensee MDPI, Basel, Switzerland. This article is an open access article distributed under the terms and conditions of the Creative Commons Attribution (CC BY) license (https:// creativecommons.org/licenses/by/ $4.0 /)$.

\begin{abstract}
The present study examines the possibility of using an industrial stirred chemical reactor, originally employed for liquid-liquid mixtures, for operating with two-phase liquid-solid suspensions. It is critical when obtaining a high-quality chemical product that the solid phase remains suspended in the liquid phase long enough that the chemical reaction takes place. The impeller was designed for the preparation of a chemical product with a prescribed composition. The present study aims at finding, using a numerical simulation analysis, if the performance of the original impeller is suitable for obtaining a new chemical product with a different composition. The Eulerian multiphase model was employed along with the renormalization (RNG) $k-\varepsilon$ turbulence model to simulate liquid-solid flow with a free surface in a stirred tank. A sliding-mesh approach was used to model the impeller rotation with the commercial CFD code, FLUENT. The results obtained underline that $25 \%$ to $40 \%$ of the solid phase is sedimented on the lower part of the reactor, depending on the initial conditions. It results that the impeller does not perform as needed; hence, the suspension time of the solid phase is not long enough for the chemical reaction to be properly completed.
\end{abstract}

Keywords: stirred tank; CFD; three-phase flow; liquid-solid; Eulerian

\section{Introduction}

The main idea behind this paper, which is the first in a series of three papers, is to develop a tractable and robust numerical approach for the design and assessment of mixing impellers, beyond the rather classical approach of selecting on-the-shelf impellers based on empirical correlations.

In the chemical industry, the employment of stirred reactors containing liquid and solid phases to obtain chemical products from the reaction between the solid-phase component and the liquid-phase component is very common. The quality of the finite chemical product is determined by the fact that the solid particles must remain in the suspension inside the liquid phase for as long as possible for the chemical reaction to take place. The sedimentation of the solid particles must be prevented by the stirring mechanism and must ensure a homogenous distribution of the solid particles in the entire volume of liquid. Another important aspect for obtaining a quality product from the chemical reaction inside the reactor is to prolong the contact time between the solid particles and the liquid phase, and the impeller plays a major role in this matter. The quality of the suspension of the solid particles generated by the impeller can be characterized by several parameters such as solid particle distribution, cloud height and suspension velocity [1-3].

The hydrodynamics of the flow process inside the stirred tanks are complex, threedimensional and turbulent. The efficiency of the mixing process that takes place inside the reactor depends on the interaction between the solid particles and the liquid, the geometry of the reactor and the design and position of the impeller. In the past three decades, computational fluid dynamics (CFDs) has proved to be a useful and substantial instrument in the chemical industry to learn about and enhance the complex phenomena of multiphase flow. A great number of studies from all over the world have performed numerical 
analyses of the turbulent multiphase flow specific to stirred reactors with different types of configurations employing different professional CFD codes (ANSYS Fluent, ANSYS CFX) [4-27].

Delafosse et al. [5] presented the numerical results of investigations carried out in a mixing tank. The aim was to identify the type of approach, URANS equations or the large eddy simulation (LES) with the Smagorinski subgrid-scale model, best suited for modeling the complex multiphase turbulent flow. The results obtained with the software Fluent, velocity distribution, were compared with PIV experimental results. The conclusion is that the URANS approach provides accurate enough results, but for greater accuracy, the LES approach is recommended.

Murthy and Joshi [6] analyzed the performances of various types of impellers and tried to assess three types of turbulence models, standard $k-\varepsilon$, the Reynolds stress model (RSM) and LES, by using the professional software Fluent. Validation of the numerical results was performed by comparison to the LDA measurement. The conclusion of the research is that the LES model provides the most accurate results but needs high computation power and a long period of time. For certain types of impellers, the standard $k-\varepsilon$ and RSM models generate satisfactory results.

Ochieng and Onyango [8] conducted an extensive review of the CFD results obtained by numerous studies in order to establish the most suitable settings for the numerical simulation of the complex flow from stirred reactors. Experimental results were also reviewed. For grid generation, it is recommended that finer grids are generated in regions of high turbulence and near the walls. From their study results, the employment of the turbulence model RNG $k-\varepsilon$ generates accurate results without a large computational power and in a decent period of time.

Taking into consideration the results of the previous studies, we decided to use the RNG $k-\varepsilon$ turbulence model, which allows sufficient accuracy of the turbulent quantities within a reasonable calculation time.

There are several research studies that recommend the employment of the VOF model for the numerical simulation of a multiphase flow. Tembely et al. [28] implemented a volume of fluid (VOF) method to analyze the two-phase flow within a porous medium that takes into account the dynamic contact angle and its hysteresis with the help of Open-source Field Operation and Manipulation (OpenFOAM). The numerical results were compared with the experimental results, and a good agreement was determined. Stachnick and Jakubowski [29] performed a numerical simulation with Ansys CFX 18.1, employing a threephase VOF model to analyze the movement and formation of deposits of solid particles from a separator used in the brewing industry. The numerical results were compared to the experimental results and proved that the model employed is suitable for the analyzed phenomena and provides accurate and reliable results for the flow and the sedimentation process. McCraney et al. [30] presented a numerical method for the symmetric draining of capillary liquids in simple corners, employing the software interFoam and the VOF model. By comparing the numerical results with the experimental results, the good accuracy of the numerical results was underlined. Silva et al. [31] employed OpenFOAM and ANSYS Fluent to study microscale gas-liquid flow. The aim of the study was to assess the capability of both software to predict the flow field by employing different models for the multiphase flow: VOF and piecewise linear interface calculation (PLIC) in ANSYS Fluent and MULES/isoAdvector in OpenFOAM. The conclusion of the research, after validating the results obtained with experimental data, is that ANSYS Fluent provides more accurate results for this type of flow. He et al. [32] presented the results of employing an improved VOF discrete element model (DEM) for studying the soil-water interaction. All the experimental observations were accurately depicted by the numerical model.

For the numerical simulation of the solid suspension from a stirred reactor, in the literature, there are also two models mentioned: the Eulerian multiphase model and the Eulerian mixture model. In the Eulerian multiphase model, continuity and momentum balance equations are solved for each phase. The Eulerian mixture model is a simplified 
version of the previous model, and it is recommended to be employed for thin mixtures and small-sized particles. For this model, continuity and momentum balance equations are solved for one mixture phase, the hydrodynamic parameters of which are computed from the mass-averaged properties of each phase. Only one equation for the transport of volume fraction is added and solved for the dispersed phase from the continuous phase. This term consists of four different interphase forces: lift force, Basset force, virtual mass force and drag force. Only the drag force can be considered in the interphase momentum exchange term because of the small influence on the entire process of the lift force, Basset and virtual mass forces.

In the literature, results obtained from using these two models are available, and these results show that the Eulerian multiphase model [10-14] provides much more accurate results than the Eulerian mixture model when working with particles with a diameter greater than $100 \mu \mathrm{m}$ and a solid fraction ranging between 0.2 and $16 \%$. The Eulerian mixture model is better adapted for small dimensions of solid particles and lower concentrations.

Taking all the previous research results into consideration, for our numerical study, the Eulerian multiphase model was best suited. Our choice for the numerical approach is also justified by the fact that the Eulerian multiphase model is not so demanding from the point of view of available power computation and computational time required for obtaining a stable solution. Boffetta et al. [33] conclude that the Eulerian model is able to generate high-accuracy results regarding the flow structure for low to moderate Stokes numbers, which is the case of our research study, where the Stokes number is 0.00038 .

The current study aims to analyze the performance of an impeller attached to a stirring mechanism regarding the distribution of the solid particles inside the liquid phase from the reactor. A schematic representation of the investigated stirred reactor is presented in Figure 1. Initially, the reactor and its stirring mechanism were developed to work only with liquid-phase components, but a reconversion of its use is needed. After analyzing the results obtained and judging the impeller performances from the point of view of solid particle distribution, a decision is taken if the impeller will be kept or another type of impeller is needed in order to ensure the prescribed solid particle distribution.

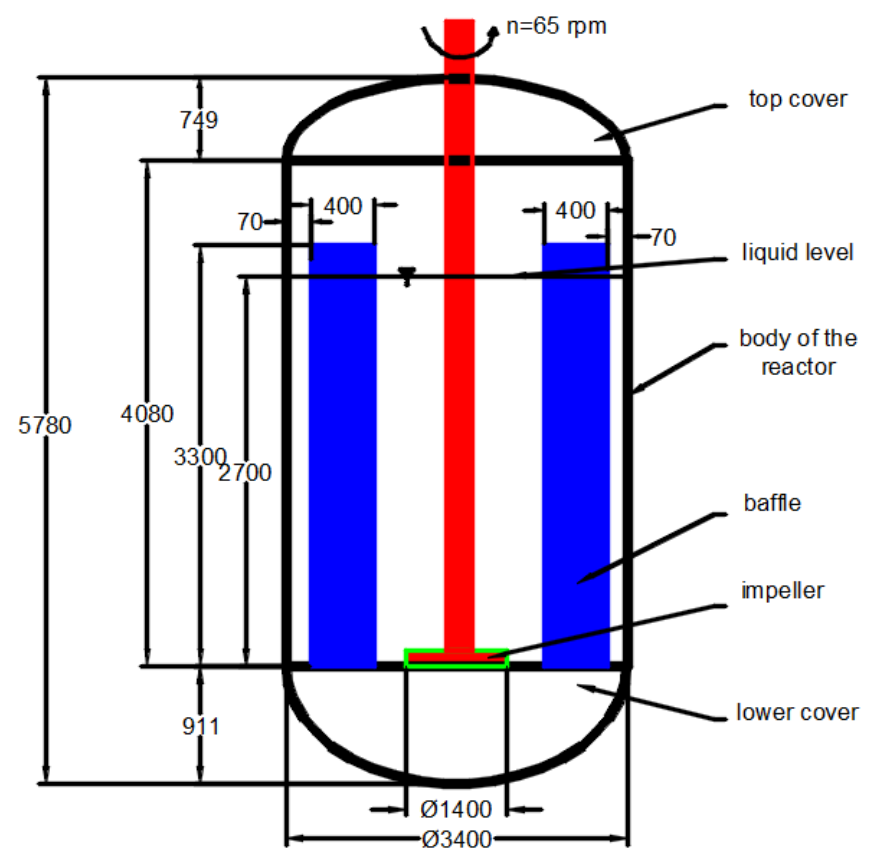

Figure 1. Schematic representation of the stirred reactor.

\section{Materials and Methods}

In this paper, the Eulerian multiphase model was chosen to describe the flow behavior of each phase of the two phases, liquid and solid. This model is the most complex, and it 
solves a set of 2 momentum equations for each phase. Coupling is achieved through the pressure and interphase exchange coefficients. The way this coupling is handled depends on the type of phases involved, and for granular flows, the properties are obtained from the application of kinetic theory. The derivation of the conservation equations for mass and momentum for each of the two phases is performed by phase-weighted averaging the local instantaneous balances for each of the phases, and then no additional turbulent dispersion term is introduced into the continuity equation. The pressure field is assumed to be shared by the two phases, in proportion to their volume fraction. The motion of each phase is governed by respective mass and momentum conservation equations.

The continuity equation for each phase is:

$$
\frac{\partial\left(\alpha_{q} \rho_{q}\right)}{\partial t}+\nabla \cdot\left(\alpha_{q} \rho_{q} \vec{v}_{q}\right)=0,
$$

where $\rho$ is the density, $\alpha$ is the volume fraction and $v$ is the velocity vector for each phase.

The conservation of momentum for the liquid and solid phase is given by the following equations:

$$
\begin{gathered}
\frac{\partial\left(\alpha_{q} \rho_{q} \overrightarrow{\vec{v}}_{q}\right)}{\partial t}+\nabla \cdot\left(\alpha_{q} \rho_{q} \vec{v}_{q} \vec{v}_{q}\right)=-\alpha_{q} \nabla p+\nabla \cdot \overrightarrow{\bar{\tau}}_{q}+\alpha_{q} \rho_{q} \vec{g}+ \\
+\sum_{q=1}^{n}\left(K_{p q}\left(\vec{v}_{p}-\vec{v}_{q}\right)+\dot{m}_{p q} \vec{v}_{p q}-\dot{m}_{q p} \vec{v}_{q p}\right)+\left(\vec{F}_{q}+\vec{F}_{l i f t, q}+\vec{F}_{q w l, q}+\vec{F}_{v m, q}+\vec{F}_{t d, q}\right) \\
\frac{\partial\left(\alpha_{s} \rho_{s} \vec{v}_{s}\right)}{\partial t}+\nabla \cdot\left(\alpha_{s} \rho_{s} \vec{v}_{s} \vec{v}_{s}\right)=-\alpha_{s} \nabla p-\nabla p_{s}+\nabla \cdot \overline{\bar{\tau}}_{s}+\alpha_{s} \rho_{s} \vec{g}+ \\
+\sum_{l=1}^{N}\left(K_{l s}\left(\vec{v}_{l}-\vec{v}_{s}\right)+\dot{m}_{l s} \vec{v}_{l s}-\dot{m}_{s l} \vec{v}_{s l}\right)+\left(\vec{F}_{s}+\vec{F}_{l i f t, s}+\vec{F}_{v m, s}+\vec{F}_{t d, s}\right) \\
\overline{\bar{\tau}}_{q}=\alpha_{q} \mu_{q}\left(\nabla \vec{v}_{q}+\nabla \vec{v}_{q}^{T}\right)+\alpha_{q}\left(\lambda_{q}-\frac{2}{3} \mu_{q}\right) \nabla \cdot \vec{v}_{q} \overline{\bar{I}}
\end{gathered}
$$

where $p$ is the pressure shared by all phases, $p_{s}$ is the solid pressure, $t_{q}$ is the $q$-th phase stress-strain tensor, $g$ is the gravitational acceleration, $\mu$ and $\lambda$ are the shear and bulk viscosity of phase $q, K_{p q}$ is the interphase momentum exchange coefficient, $K_{l s}$ is the momentum exchange coefficient between fluid or solid, $F_{q}$ is an external body force, $F_{l i f t, q}$ is a lift force, $F_{w l, q}$ is a wall lubrication force, $F_{v m, q}$ is a virtual mass force, $F_{t d, q}$ is a turbulent dispersion force and $v_{p q}$ is the interphase velocity.

Only the contribution of the drag force was taken into consideration because previous studies $[2,10,12]$ showed that the other forces have no major effect on both the liquid-gas and liquid-solid hydrodynamics in stirred reactors.

Almost all definitions of the drag function $(f)$ include a drag coefficient $\left(C_{D}\right)$ that is based on the relative Reynolds number $(R e)$. It is this drag function that differs among the exchange coefficient models. For the present work, the Morsi and Alexander model was used, which is the most complete [25]:

$$
\begin{gathered}
f=\frac{C_{D} \operatorname{Re}}{24} \\
C_{D}=0.5191-\frac{1662.5}{\operatorname{Re}}+\frac{5416700}{\operatorname{Re}^{2}}
\end{gathered}
$$

The fluid-solid exchange coefficient $\left(K_{s l}\right)$ can be written as a function of the solid particle relaxation time $\left(\tau_{s}\right)$, volume fraction of the solid phase $\left(\alpha_{s}\right)$, density of the solid phase $\left(\rho_{s}\right)$ and drag function $(f)$ :

$$
\begin{aligned}
K_{s l} & =\frac{\alpha_{s} \rho_{s} f}{\tau_{s}} \\
\tau_{s} & =\frac{\rho_{s} d_{s}^{2}}{18 \mu_{l}}
\end{aligned}
$$

For the present research work, the Huilin-Gidaspow model was employed, which is a combination of the Wen and Yu model and the Ergun equation:

$$
\begin{gathered}
K_{s l}=\psi K_{s l-E r g u n}+(1-\psi) K_{s l-W e n \& \gamma u} \\
\psi=\frac{1}{2}+\frac{\arctan \left(262.5\left(\alpha_{s}-0.2\right)\right)}{\pi}
\end{gathered}
$$


The RNG $k-\varepsilon$ model with the dispersed option was chosen for simulating the turbulence in the present study. The dispersed turbulence model is the appropriate model when using the granular model. Fluctuating quantities of the secondary phases can be given in terms of the mean characteristics of the primary phase and the ratio of the particle relaxation time and eddy-particle interaction time. The Reynolds stress tensor for continuous phase $q$ takes the following form [25]:

$$
\overline{\bar{\tau}}_{q}^{\prime \prime}=-\frac{2}{3}\left(\rho_{q} k_{q}+\rho_{q} v_{t, q} \nabla \cdot \vec{v}_{q}\right) \overline{\bar{I}}+\rho_{q} v_{t, q}\left(\nabla \vec{v}_{q}+\nabla \vec{v}_{q}^{T}\right)
$$

where $v_{\mathrm{q}}$ is the phase-weighted velocity.

The turbulent viscosity is written in terms of the turbulent kinetic energy of phase $q$, and the characteristic time of the energetic turbulent eddies is defined as

$$
\begin{aligned}
& \mu_{t, q}=\rho_{q} C_{\mu} \frac{k_{q}^{2}}{\varepsilon_{q}} \\
& \tau_{t, q}=\frac{3}{2} C_{\mu} \frac{k_{q}}{\varepsilon_{q}}
\end{aligned}
$$

where $\varepsilon_{q}$ is the dissipation rate, and $C_{\mu}=0.09$.

The length scale of the turbulent eddies is given by:

$$
L_{t, q}=\sqrt{\frac{3}{2}} C_{\mu} \frac{k_{q}^{3 / 2}}{\varepsilon_{q}}
$$

Turbulent predictions are obtained from the modified $k-\varepsilon$ model. The transport equations (excluding buoyancy, dilation and user-defined terms) are:

$$
\begin{aligned}
& \frac{\partial}{\partial t}\left(\alpha_{q} \rho_{q} k_{q}\right)+\nabla \cdot\left(\alpha_{q} \rho_{q} \vec{v}_{q} k_{q}\right)=\nabla \cdot\left(\alpha_{q}\left(\mu_{q}+\frac{\mu_{t, q}}{\sigma_{k}}\right) \nabla k_{q}\right) \\
& +\alpha_{q} G_{k, q}-\alpha_{q} \rho_{q} \in_{q}+\alpha_{q} \rho_{q} \Pi_{k, q} \\
& \frac{\partial}{\partial t}\left(\alpha_{q} \rho_{q} \varepsilon_{q}\right)+\nabla \cdot\left(\alpha_{q} \rho_{q} \vec{v}_{q} \varepsilon_{q}\right)=\nabla \cdot\left(\alpha_{q}\left(\mu_{q}+\frac{\mu_{t, q}}{\sigma_{\varepsilon}}\right) \nabla \varepsilon_{q}\right) \\
& +\alpha_{q} \frac{\varepsilon_{q}}{k_{q}}\left(C_{1 \varepsilon} G_{k, q}-C_{2 \varepsilon} \rho_{q} \varepsilon_{q}\right)+\alpha_{q} \rho_{q} \Pi_{\varepsilon, q}
\end{aligned}
$$

where $\Pi_{k q}$ and $\Pi_{\varepsilon q}$ are source terms that can be included to model the influence of the dispersed phases on the continuous phase $q$, and $G_{k, q}$ is the production of turbulent kinetic energy.

In the present research, the granular temperature of the solid phase was specified by an algebraic equation.

$$
0=\left(-p_{s} \overline{\bar{I}}+\overline{\bar{\tau}}_{s}\right): \nabla \vec{v}_{s}-\gamma_{\Theta_{s}}+\varphi_{l s}
$$

where $0=\left(-p_{s} \overline{\bar{I}}+\overline{\bar{\tau}}_{s}\right): \nabla \vec{v}_{s}$ represents the generation of energy by the solid stress tensor, $\gamma_{\Theta_{s}}$ is the collisional dissipation of energy and $\varphi_{l s}$ is the energy exchange between the l-th fluid phase and the s-th solid phase.

Geometry reconstruction of the industrial stirred reactor and its meshing were performed with the software Gambit 2.4. The mesh consists of approximately 1.1 million tetrahedral elements. As regards the mesh quality, we were restricted to use tetra mesh elements due to a greater number of previous case studies [2,3]. For our numerical investigation, a very high quality of mesh (skewness $<0.6$ ) was ensured throughout the computational domain.

In order to use the sliding-mesh method, four fluid zones were defined: an inner rotating cylindrical volume centered on the impeller and three other volumes containing the rest of the reactor and the baffles. The interface is located at an equal distance from the blades of the impeller and the inside edge of the baffles. An illustration of the domain and the mesh of the domain is given in Figure 2, which shows that finer meshes were used around the impeller where the velocity spatial gradients are expected to be large. Good care was taken in keeping the same mesh dimension between the rotating and the stationary interface to ensure a good exchange of the hydrodynamic quantities between the two zones during calculation. A "no-slip" condition was applied on all walls of the geometry. 


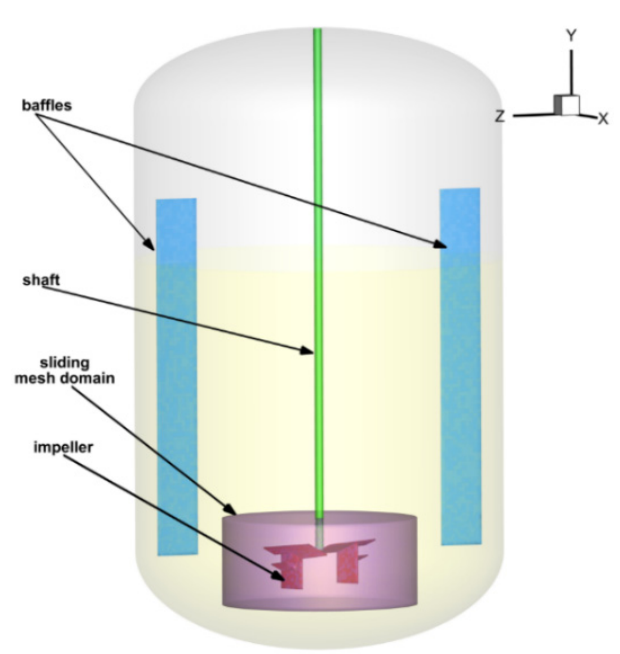

(a)

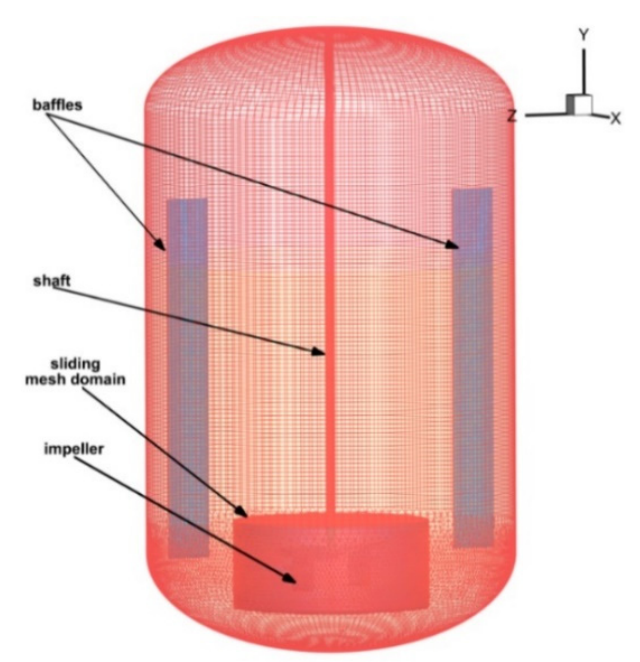

(b)

Figure 2. Computational domain: (a) components of the reactor; (b) mesh of the computational domain.

Simulations of the turbulent multiphase flow were then performed with the help of the commercial CFD code Fluent 16 using the RNG $k-\varepsilon$ model. There are two working materials corresponding to the two phases, liquid and solid: liquid with density $\rho_{l}=690 \mathrm{~kg}^{*} \mathrm{~m}^{-3}$, powder with density $\rho_{p}=1520 \mathrm{~kg}^{*} \mathrm{~m}^{-3}$ and particle size $d=0.000171 \mathrm{~m}$. At the liquid surface, a gas zone consisting of air was added at the free surface of water, a method that has been reported to dampen the instabilities, which means the top surface is exposed to atmospheric pressure. The flow resolution was unsteady, and the sliding-mesh approach was employed. At each time step, the position of the rotating zone relative to the stationary one was recomputed, and the grid interface of the rotating zone slid along the interface of the stationary zone. For all simulations, the time step was set as a function of the impeller speed, $65 \mathrm{rot} / \mathrm{min}$, and the number of the cells from the interface surface, approximately 140 elements, so the time step was set to a value of $0.01 \mathrm{~s}$.

At the end of each time step, after a maximum of 5 iterations, the convergence criterion reached 1 - for the continuity, momentum and turbulence quantities. This value of the convergence criteria was set to have a total computational time of $120 \mathrm{~h}$. Although the value of the criteria might be considered to be a course for complex Eulerian multiphase flow, the objective of the current research was to obtain an accurate enough result in a short period of time in order to make a practical decision. Simulations were performed in double precision with the segregated implicit solver. Transient formulation was of the first order, and the spatial discretization scheme for pressure was PRESTO! and for momentum and turbulence was QUICK. The SIMPLE algorithm was employed for the pressure-velocity coupling [15-20]. The analysis of the results was performed after a total flow time of $90 \mathrm{~s}$.

\section{Results and Discussion}

For chemical multiphase reactions, the hydrodynamic field plays a major role in the mixing of the two phases and in the mass transfer. The impact of the hydrodynamic field upon the performances of an industrial stirred reactor is determined by the specific geometry of the reactor. For reactors operating with a two-phase flow, solid and liquid, it is recommended to monitor the solid particle distribution to check if the distribution is in line with the prescribed condition of the chemical process. For certain chemical reactions, it is mandatory that the solid particles float inside the liquid phase close to the lower part of the reactor. For other situations, such as in the case we analyzed, it is required that the solid particles are distributed uniformly throughout the entire liquid-phase volume. The experimental methods of investigations based on PIV or LDV are recommended to analyze the hydrodynamic field from inside the reactor; however, because of technical limitations, in our case, the reactor was made out of steel, and only CFD could be employed 
to determine the flow structure. The performance of the industrial reactor requires the solid particles to remain in the suspension in the entire volume of the liquid phase for a long enough period of time so that the chemical reactions between the two phases take place. If the solid phase is not homogenously distributed in the liquid phase and it settles on the bottom of the reactor, it results in the waste of the chemical ingredients and the failure to obtain the desired final chemical product with the prescribed characteristics.

There are two cases studied in this paper and the results analyzed: the first case considers that the solid particles are already settled at the bottom of the reactor before the impeller starts to rotate (Figure 3a), and for the second case, it was considered that the solid particles are all in the suspension when the impeller starts to rotate (Figure 3b). Figure $3 a, b$ represents the distribution of the volume fraction of the solid phase in the entire 3D reactor and on a vertical plane.

The most relevant quantitative representation for the analysis of the performance of the stirring mechanism is represented by the histogram of the distribution of the volume fraction of the solid phase. Similar representations of the numerical results were given by Gohel et al. [3], Panneerselvam et al. [7] and Montante [21]. Thereby, the initial state with the homogenous distribution of the solid phase in the entire volume of the liquid phase corresponds to an optimum solid volume concentration of $18.2 \%$ (Figure $3 b$ ). For the first case (Figure 3a), where the solid phase is completely sedimented in the lower part of the reactor, the solid volume concentration has a value of $63 \%$, and the remaining $42 \%$ of the entire volume of liquid contains no solid phase. The analysis of the volume fraction of the solid phase distribution presented in Figure 4 underlines the fact that the rotation of the impeller did not avoid the sedimentation of the solid phase on the bottom of the reactor for both analyzed situations. It results that the first situation analyzed (Figure 4a) is the most unfavorable situation from the point of view of solid-phase sedimentation. The histograms of the distribution of the volume fraction of the solid phase presented in Figure $4 a, b$ confirm that this impeller did not perform properly. In the first case (Figure $4 a$ ), almost $40 \%$ of the volume of the liquid phase does not contain solid particles, and for the second case (Figure $4 \mathrm{~b}$ ), almost $23 \%$ of the volume of the liquid phase does not contain solid particles.

By analyzing Figure $4 a, b$, it results that it is the best option to start the operation of the stirring mechanism when the solid phase is not completely sedimented on the lower part of the reactor. Even for this situation, the impeller does not avoid the sedimentation of a consistent part of the solid phase on the bottom of the reactor.

The poor operation of the impeller, in both analyzed situations, is also underlined by the axial and radial distribution of the volume fraction distribution of the solid phase (Figure 5).

The investigation of the hydrodynamic performance of the impeller is based on the velocity vector distribution of the liquid phase in order to analyze the flow pattern as mentioned by Calvo et al. [4] and Hoseini et al. [22], who obtained similar results.

Figure 6 presents the velocity vector distribution of the liquid phase on two vertical planes, the upper two pictures, and on one the horizontal plane, the lower two pictures. It can be observed that two vortexes are generated between the impeller and the two baffles, where the liquid is pushed toward the bottom of the reactor and then goes upwards. The hydrodynamic field of the liquid generated by the impeller did not prove to be adequate to maintain the solid phase suspended off the bottom of the reactor. 


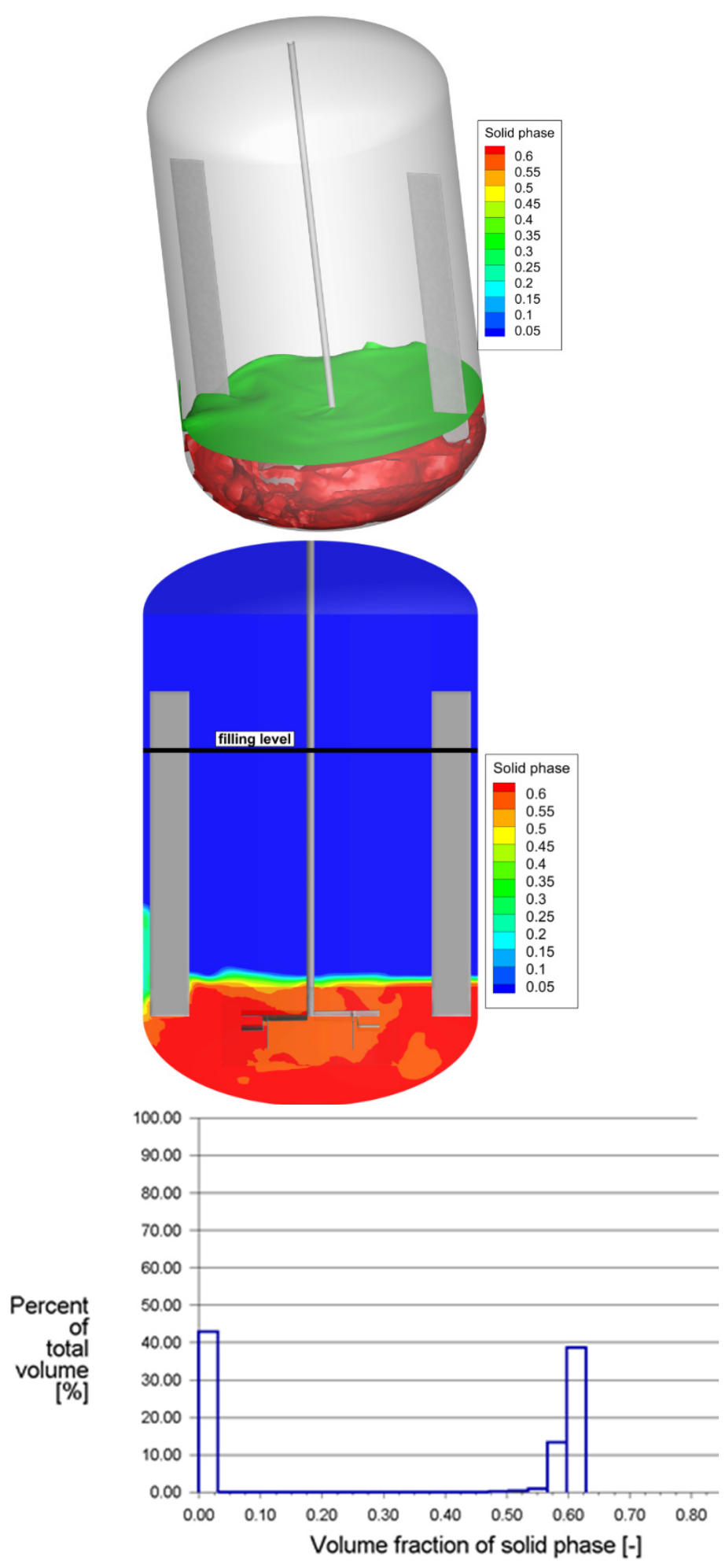

(a)

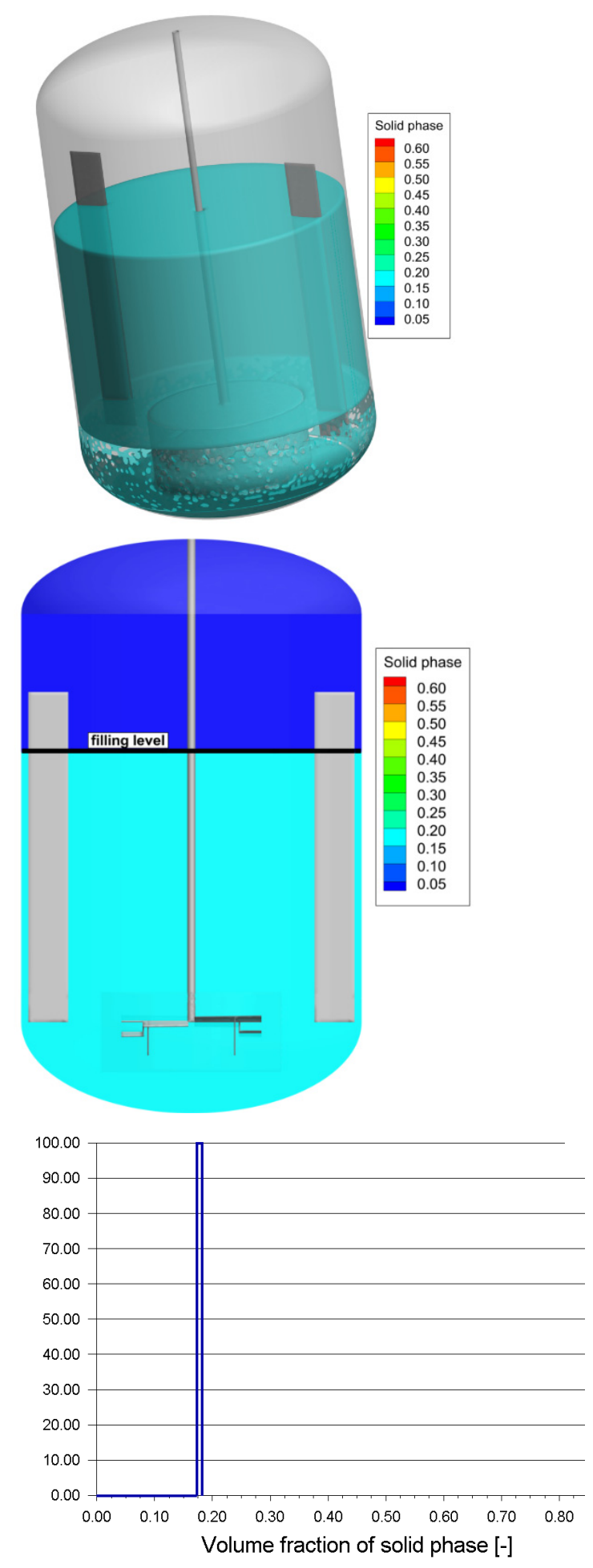

(b)

Figure 3. Initial state of the volume fraction distribution of the solid phase: (a) flow started from the solid phase fully sedimented; (b) flow started from the solid phase dispersed in the entire volume of liquid. 

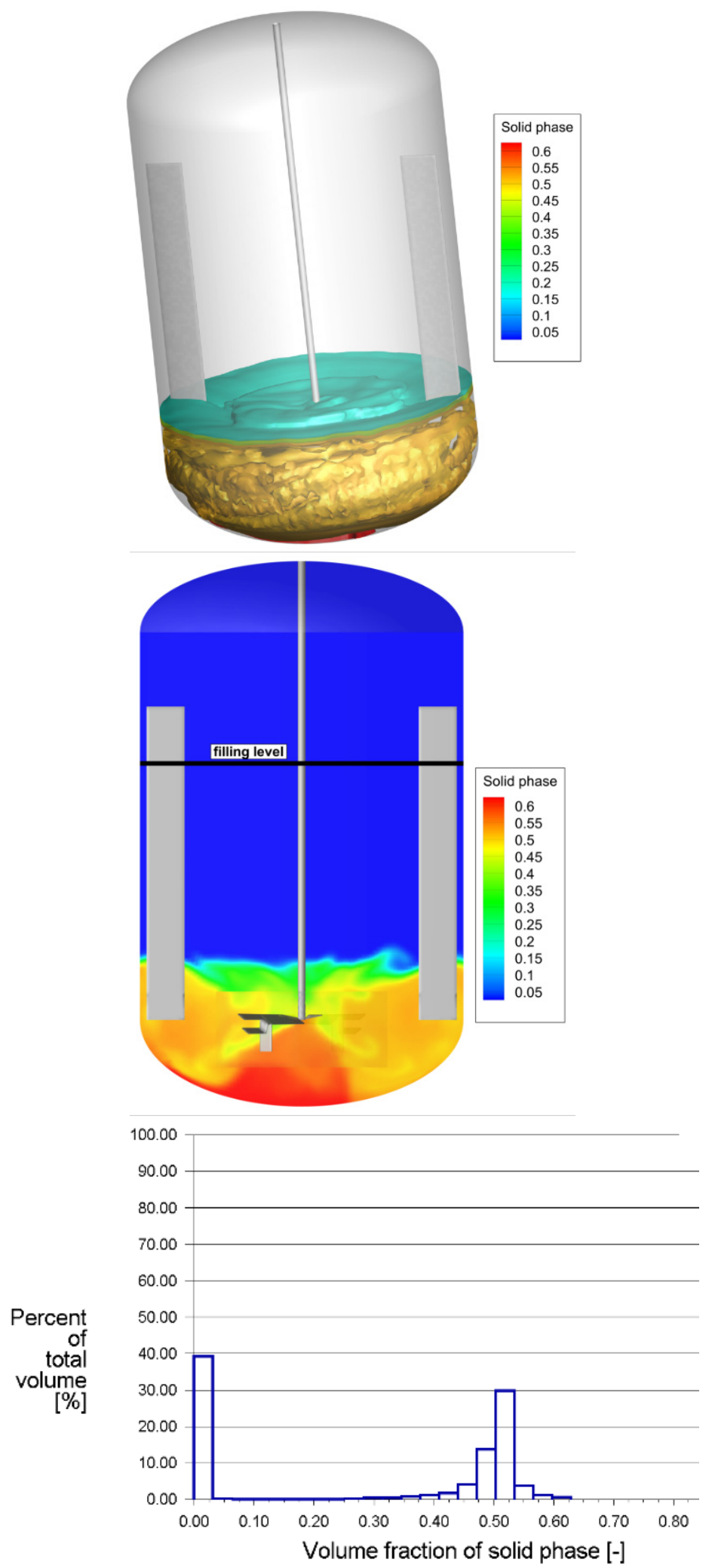

(a)
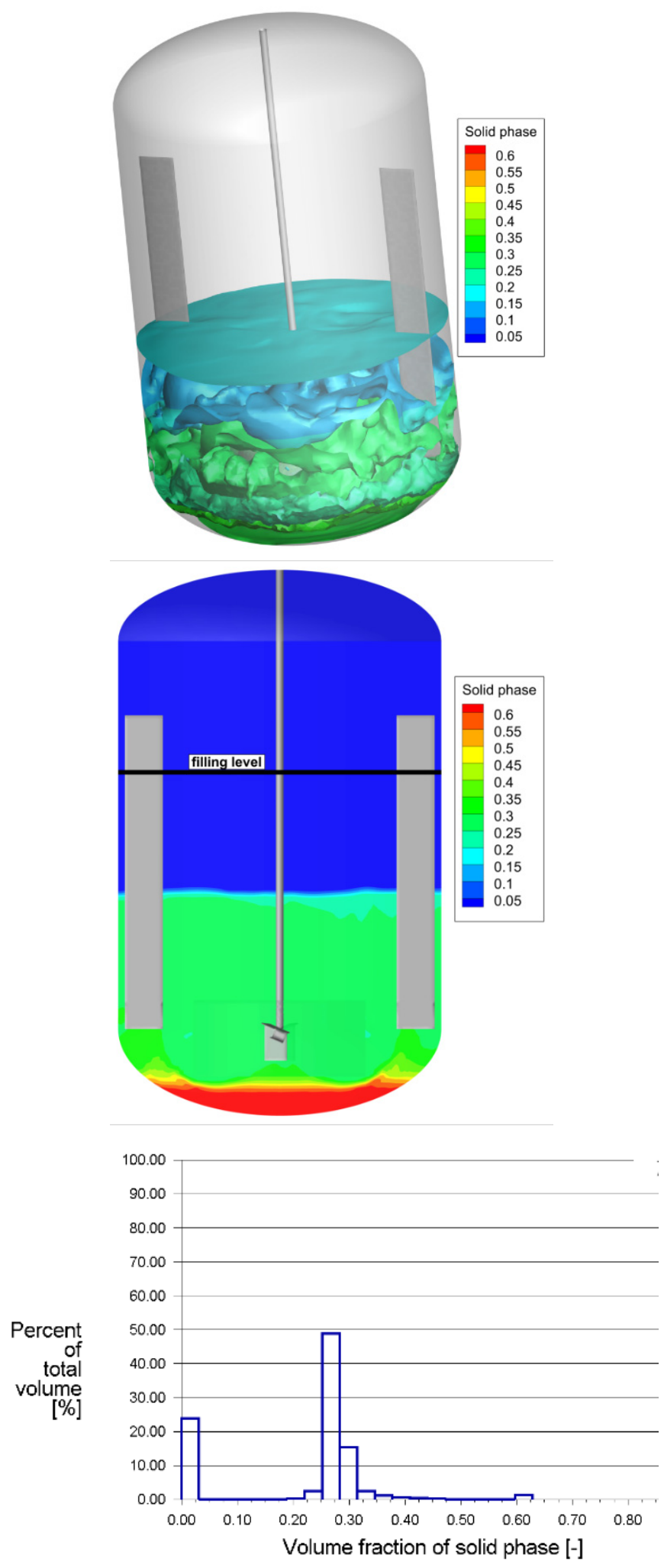

(b)

Figure 4. Final state of the volume fraction distribution of the solid phase: (a) flow started from the solid phase fully sedimented; (b) flow started from the solid phase dispersed in the entire volume of liquid. 


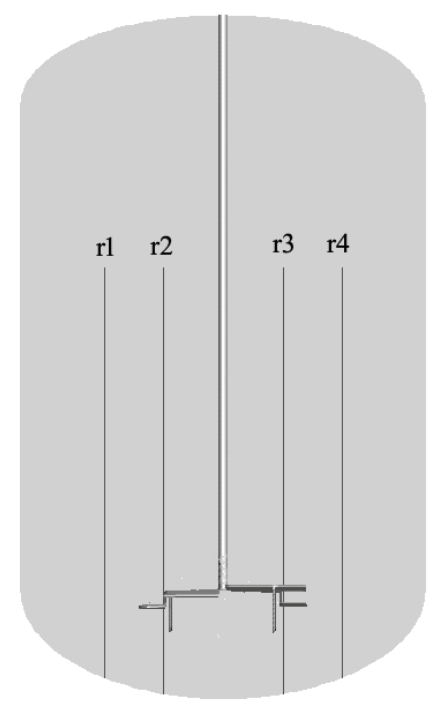

Radial probe lines

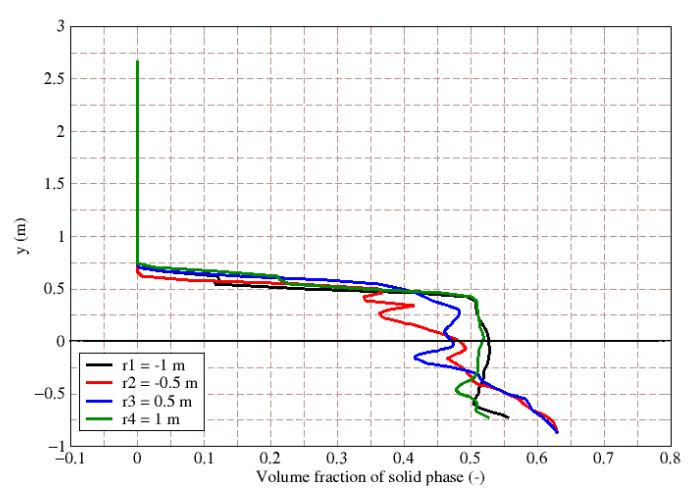

Axial probe lines

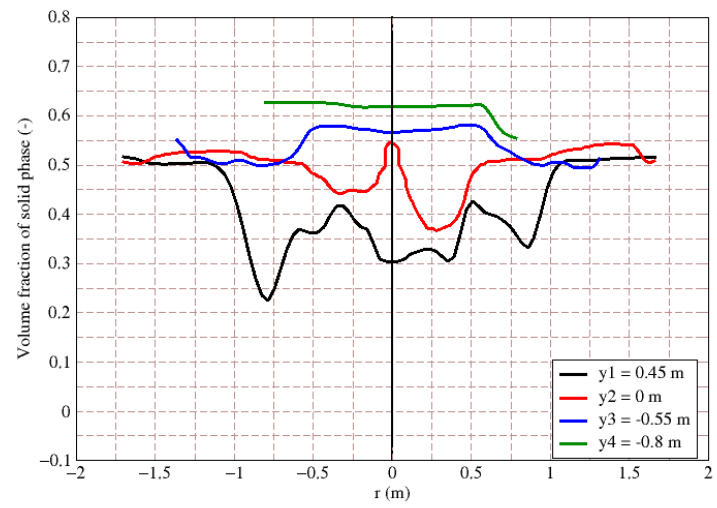

(a)

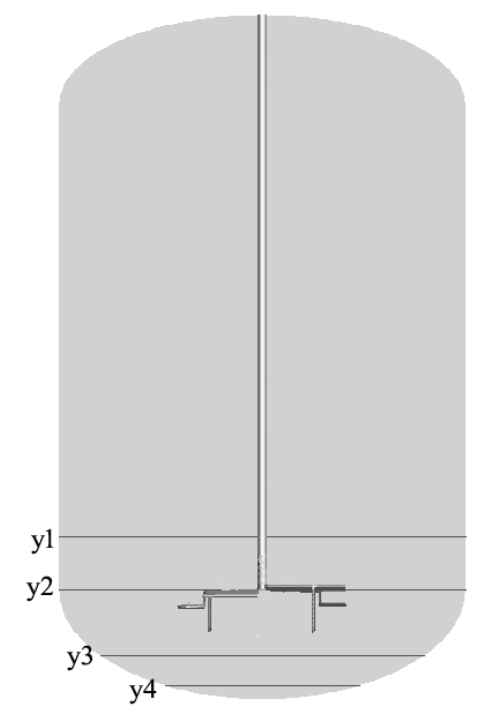

Radial probe lines

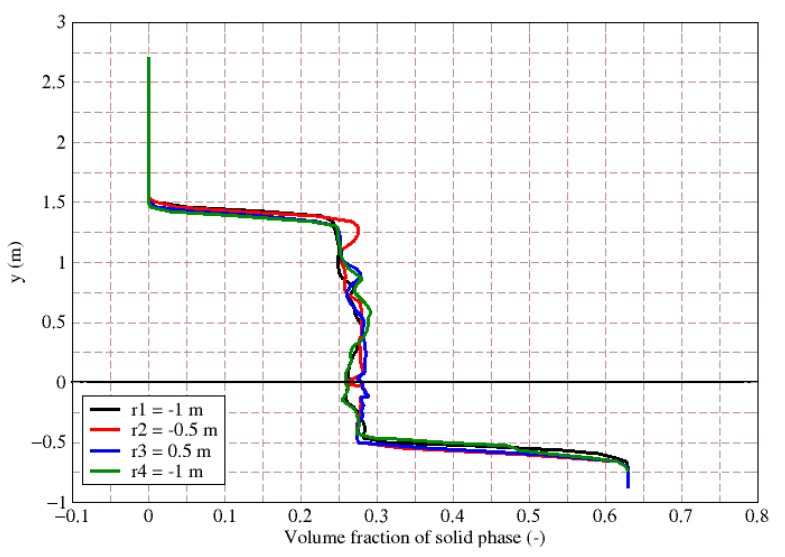

Axial probe lines

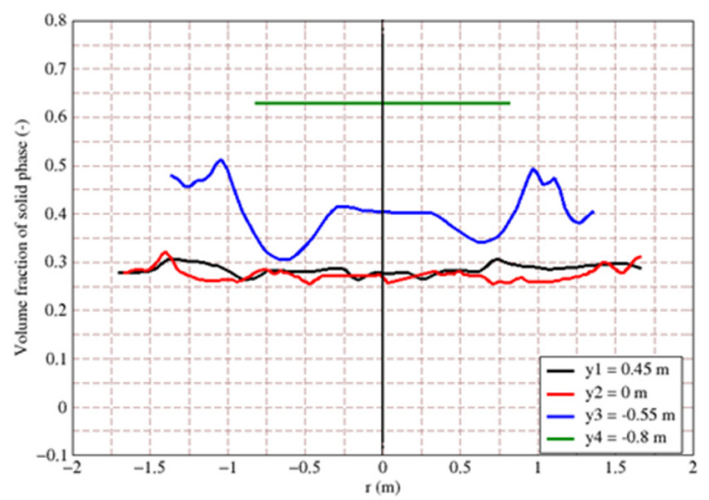

(b)

Figure 5. Final state of the volume fraction distribution of the solid phase axially and radially: (a) flow started from the solid phase fully sedimented; (b) flow started from the solid phase dispersed in the entire volume of liquid. 


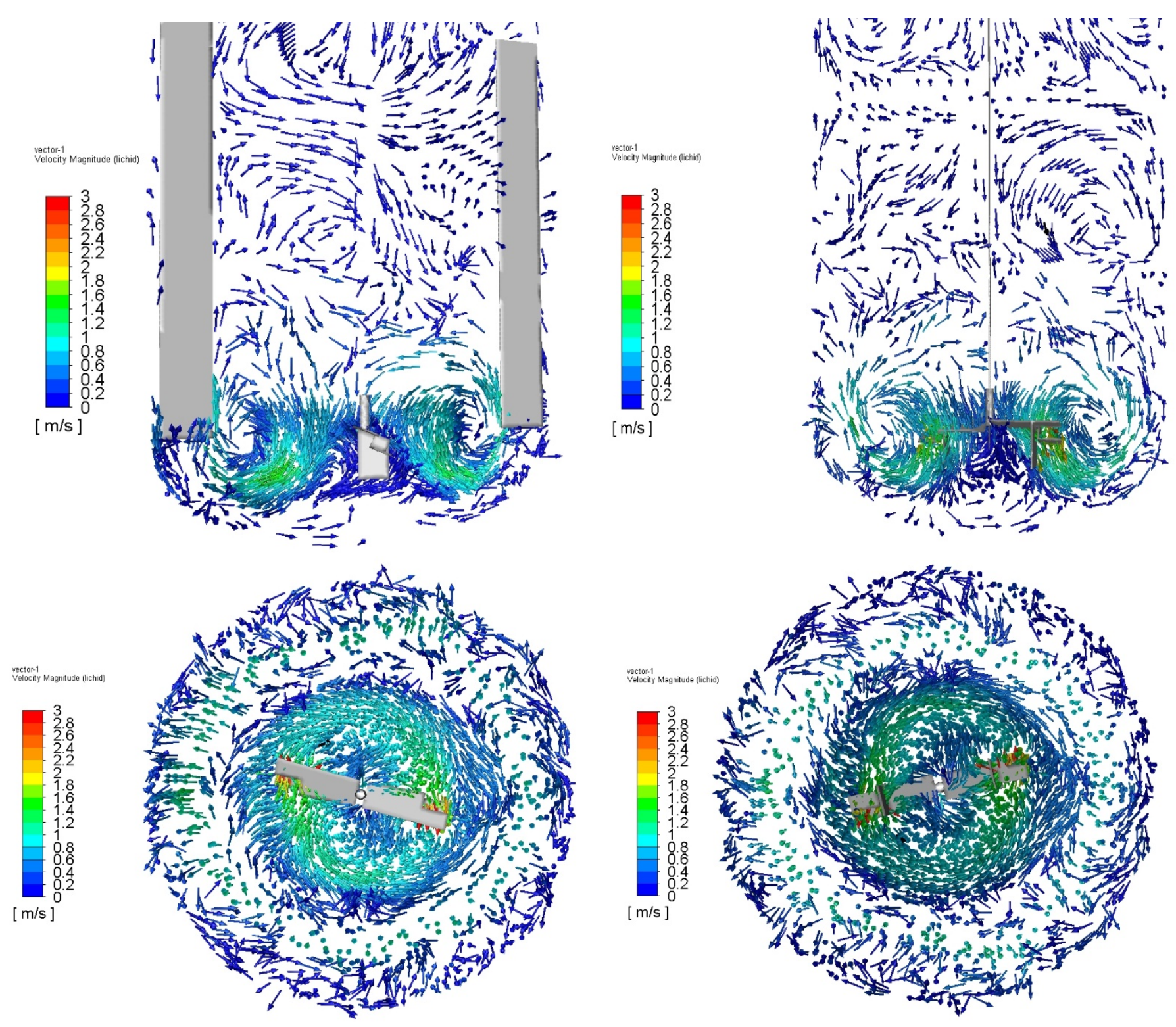

Figure 6. Velocity vector distribution of the liquid phase.

Figure 7 presents the distribution of the axial component of the liquid velocity along a vertical plane. It can be observed that in both cases, the liquid flows toward the bottom of the reactor, but it does not reach the very bottom, and then it goes upward. In the case of the homogeneous solid-phase distribution (Figure $7 \mathrm{~b}$ ), the zones with higher velocity values are larger than in the other case (Figure 7a), but that is not enough to have a completely suspended solid phase.

From the distribution of the radial component of the velocity of the liquid (Figure 8), it results that the extension of the zones with positive and negative values of the velocity are similar. In both situations, the movement of the liquid is oriented toward the shaft before entering the impeller, and after exiting the impeller, the flow is directed toward the walls of the reactor.

For the two analyzed situations, there is a clear difference in the tangential velocity distribution. Analyzing the distribution of the tangential component of the liquid velocity, it can be observed that there are higher values for this component for the case of the initial homogeneous distribution of the solid phase (Figure 9b). For the situation of the homogenous distribution of the solid phase, it can be observed that the best-suited 
tangential velocity distribution is generated by the impeller for preventing the solid phase from settling on the lower part of the reactor in a large quantity.

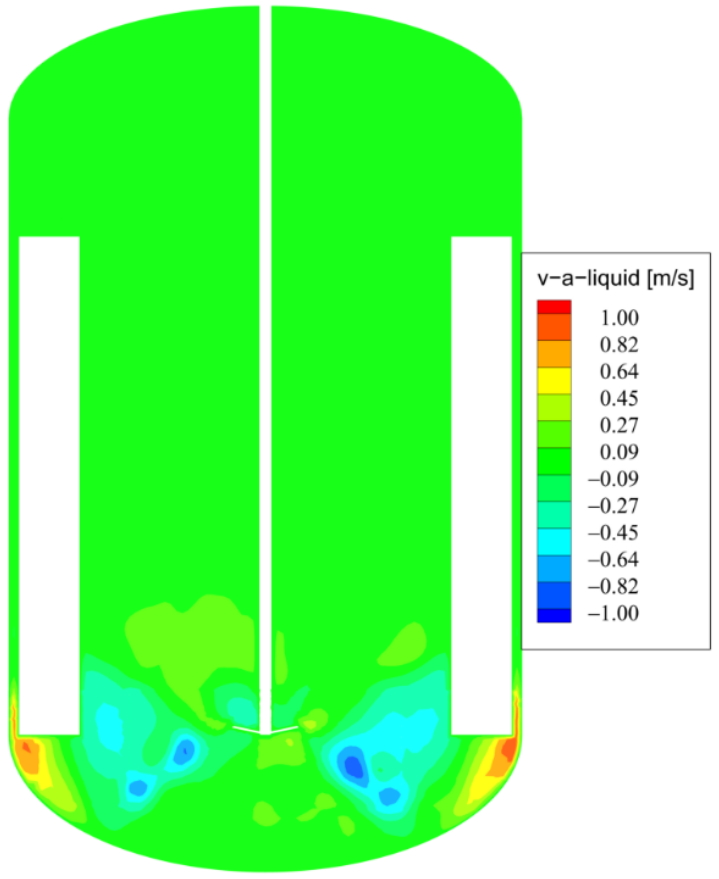

(a)

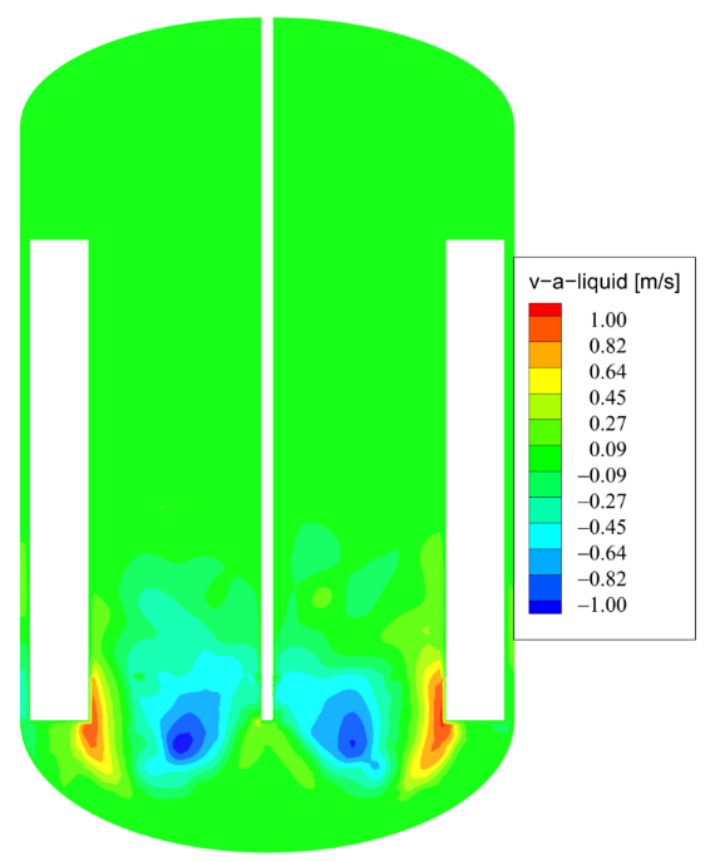

(b)

Figure 7. Axial velocity distribution of the liquid phase: (a) flow started from the solid phase fully sedimented; (b) flow from the solid phase dispersed in the entire volume of liquid.
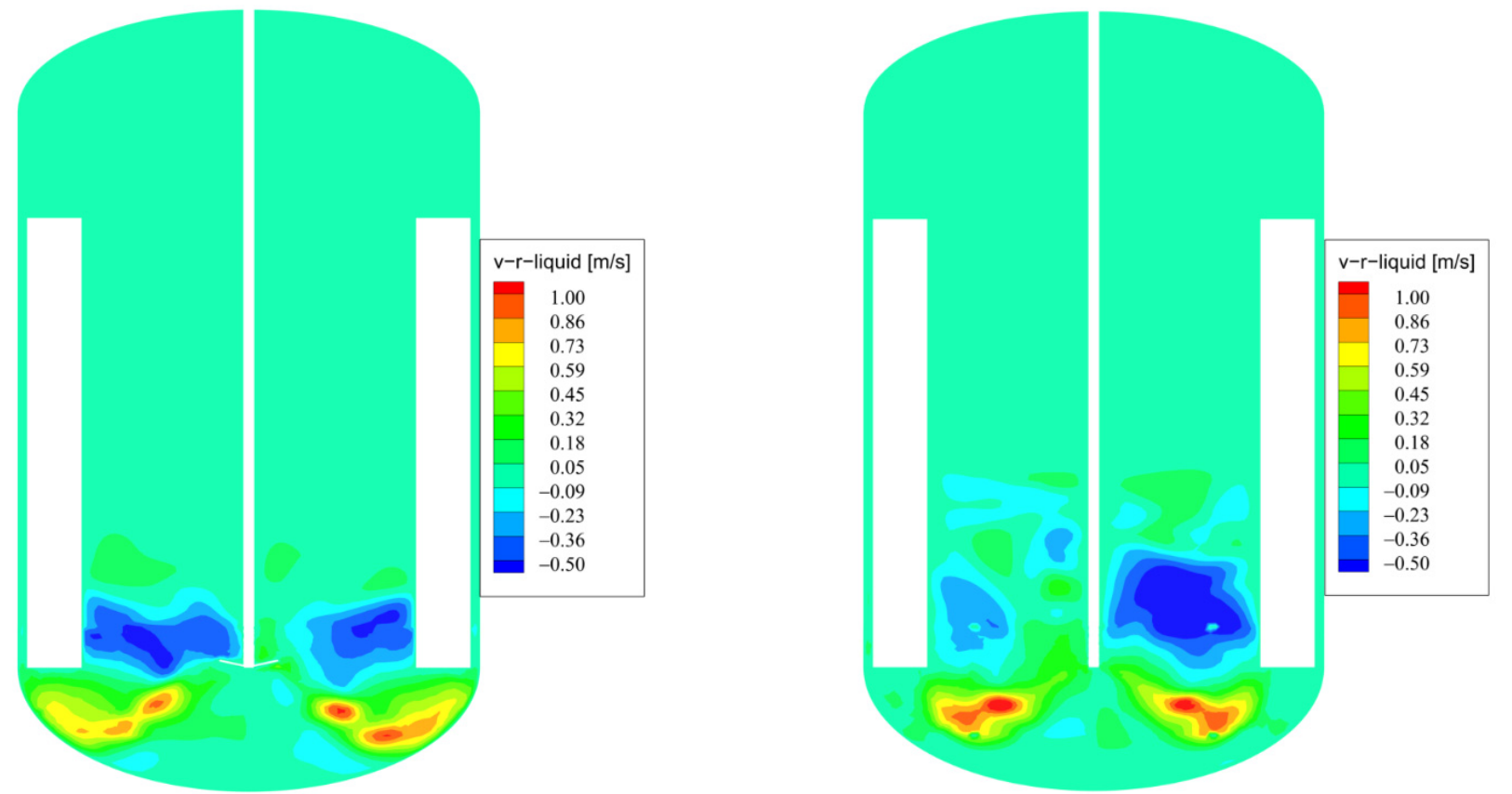

Figure 8. Radial velocity distribution of the liquid phase: (a) flow started from the solid phase fully sedimented; (b) flow started from the solid phase dispersed in the entire volume of liquid. 


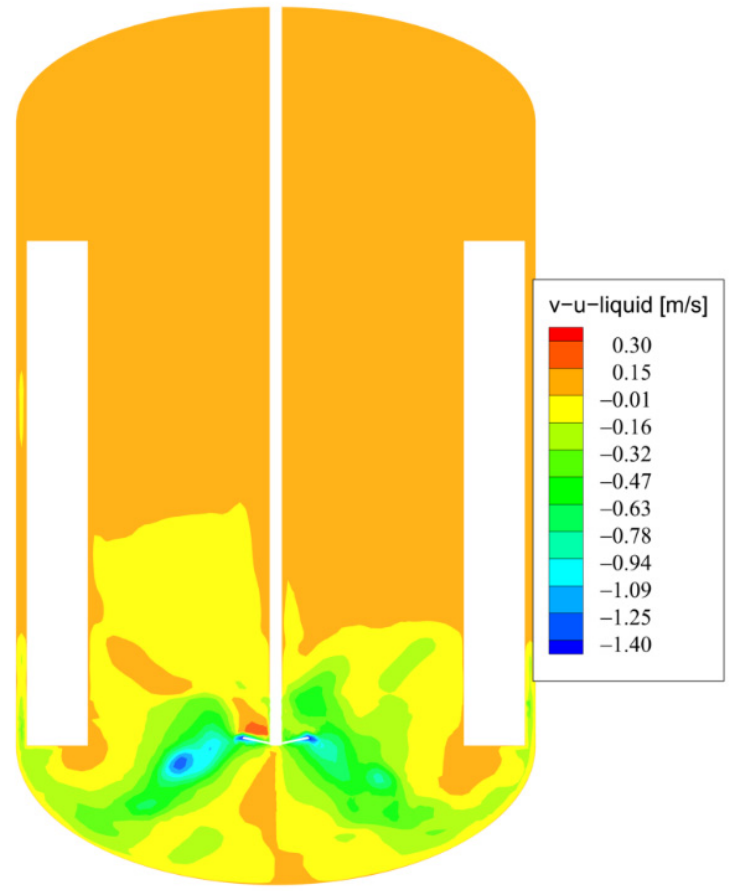

(a)

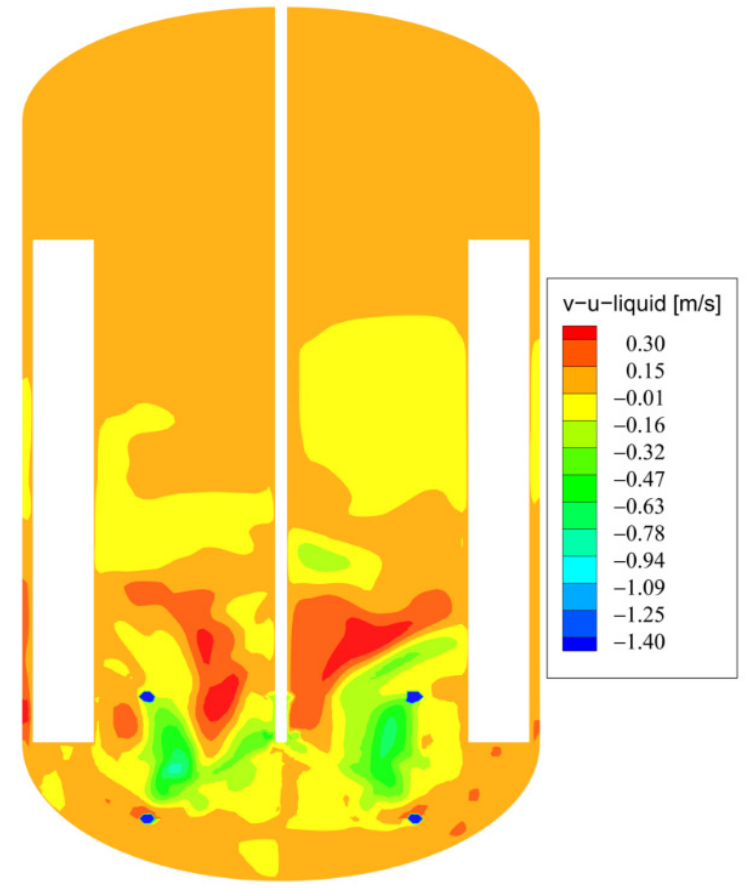

(b)

Figure 9. Tangential velocity distribution of the liquid phase: (a) flow started from the solid phase fully sedimented; (b) flow started from the solid phase dispersed in the entire volume of liquid.

Considering that, originally, the reactor operated with a liquid-liquid substance combination, another investigated aspect was to see if the stirring mechanism can be used for the new two-phase flow from the point of view of the power generated by the electrical motor. From the numerical simulation of the operation of the impeller with this two-phase flow, it resulted that the necessary power to drive the impeller has the value of $2.05 \mathrm{~kW}$. This value is smaller than $3.6 \mathrm{~kW}$, the power generated by the electrical motor, which drives the stirring mechanism. It results that the current stirring mechanism is able to ensure the needed power for the impeller to work in the new conditions with the two-phase flow.

\section{Conclusions}

This paper presents the results of the CFD analysis of stirring a liquid-solid suspension in an industrial reactor. The numerical analysis of the flow inside the reactor was conducted using expert software Fluent 16 with the Eulerian multiphase model for modeling the two-phase flow and the RNG $k-\varepsilon$ model for turbulence. The sliding-mesh approach was used for modeling the rotation of the stirring mechanism.

The aim of this paper was to assess the capability of the impeller to generate a hydrodynamic field that would keep the entire solid phase off the bottom of the reactor with the desired uniform distribution in the bulk of the liquid phase. Two cases were analyzed: one where the impeller starts to operate when the solid phase is initially completely settled on the bottom of the reactor and one where the impeller starts to operate when the solid phase is initially homogenously distributed in the entire volume of liquid. To analyze the performance of the impeller, the distribution of the volume fraction of the solid phase was plotted on a vertical plane, on the entire 3D domain and on a histogram after $90 \mathrm{~s}$ of flow time. The hydrodynamic performances of the impeller were also analyzed with the help of the velocity vector distribution on one horizontal and one vertical plane and with the help of the velocity components axial, radial and tangential plotted on a vertical plane through the middle of the reactor.

From the analysis of these entire data, for both investigated cases, it resulted that the original two-blade impeller was not able to generate a hydrodynamic field that could keep 
the entire solid phase in the suspension. At the end of the flow time, a part of the solid phase was sedimented on the bottom of the reactor. The volume fraction of the solid phase sedimented was larger for the first case investigated, proving that the impeller is not able to lift the already sedimented solid phase. Even when the simulation is started with a homogeneous solid suspension, unacceptable sedimentation still occurs.

Another conclusion of the research is that the power required by the stirring system is not significantly changed when operating with a liquid-solid suspension.

As a result, a proper stirring of the liquid-solid suspension requires a new design for the impeller able to generate a suitable flow that prevents the sedimentation, which hinders the chemical reaction.

Author Contributions: Investigation, A.S. and A.B.; Methodology, A.S and R.S.-R.; Supervision, R.S.-R.; Writing-review \& editing, A.S. All authors have read and agreed to the published version of the manuscript.

Funding: This research was funded by grant number 50/2017.

Institutional Review Board Statement: Not applicable.

Informed Consent Statement: Not applicable.

Data Availability Statement: Not applicable.

Conflicts of Interest: The authors declare no conflict of interest.

\section{References}

1. Paul, E.L.; Atiemo-Obeng, V.A.; Kresta, S.M. Handbook of Industrial Mixing; John Wiley\&Sons: Hoboken, NJ, USA, 2004.

2. Murthy, B.N.; Ghadge, R.S.; Joshi, J.B. CFD simulations of gas-liquid-solid stirred reactor: Prediction of critical impeller speed for solid suspension. Chem. Eng. Sci. 2007, 62, 7184-7195. [CrossRef]

3. Gohel, S.; Joshi, S.; Azhar, M. CFD modeling of solid suspension in a stirred tank: Effect of drag models and turbulent dispersion on cloud height. Int. J. Chem. Eng. 2012, 2012, 9. [CrossRef]

4. Calvo, S.; Delafosse, A.; Collignon, M.L.; Crine, M.; Toye, D. Experimental characterization and modelling of homogeneous solid suspension in an industrial stirred tank. Adv. Mech. Eng. 2013, 2013, 9.

5. Delafosse, A.; line, A.; Morchain, J.; Guiraud, P. LES and URANS simulations of hydrodynamics in mixing tank: Comparison to PIV experiments, Chem. Eng. Res. Des. 2008, 86, 1322-1330. [CrossRef]

6. Murthy, B.N.; Joshi, J.B. Assessment of standard k- $\varepsilon$, RSM and LES turbulence models in a baffled stirred vessel agitated by various impeller designs. Chem. Eng. Sci. 2008, 63, 5468-5495. [CrossRef]

7. Panneerselvam, R.; Savithri, S.; Surender, G.D. CFD modeling of gas-liquid-solid mechanically agitated contactor. Chem. Eng. Res. Des. 2008, 86, 1331-1344. [CrossRef]

8. Ochieng, A.; Onyango, M.S. CFD simulation of solid suspension in stirred tanks: Review. Hem. Ind. 2010, 64, 365-374. [CrossRef]

9. Kasat, G.R.; Khopkar, A.R.; Ranade, V.V.; Pandit, A.B. CFD simulation of liquid-phase mixing in solid-liquid stirred reactor. Chem. Eng. Sci. 2008, 63, 3877-3885. [CrossRef]

10. Montante, G.; Micale, G.; Magelli, F.; Brucato, A. Experiments and CFD prediction of solid particle distribution height in a vessel agitated with four pitched blade turbines. Chem. Eng. Res. Des. 2001, 79, 1005-1010. [CrossRef]

11. Micale, G.; Grisafi, F.; Rizzuti, L.; Brucato, A. CFD simulation of particle suspension height in stirred vessels. Chem. Eng. Res. Des. 2004, 82, 1204-1213. [CrossRef]

12. Khopkar, A.R.; Kasat, G.R.; Pandit, A.B.; Ranade, V.V. Computational fluid dynamics simulation of the solid suspension in a stirred slurry reactor. Ind. Eng. Chem. Res. 2006, 45, 4416-4428. [CrossRef]

13. Micale, G.; Montante, G.; Grisafi, F.; Brucato, A.; Godfrey, J. CFD simulation of particle distribution in stirred vessels. Chem. Eng. Res. Des. 2000, 78, 435-444. [CrossRef]

14. Wadnerkar, D.; Utikar, R.P.; Tade, M.O.; Pareek, V.K. CFD simulation of solid-liquid stirred tanks. Adv. Powder Technol. 2012, 23, 445-453. [CrossRef]

15. Anton, A.A.; Muntean, S.; Susan-Resiga, R.F. An interface tracking algorithm for computing the two-dimensional swirling flows with stagnant region. Proc. Rom. Acad. 2016, 17, 366-373.

16. Anton, A.A.; Cretu, V.I.; Ruprecht, A.; Muntean, S. Traffic Replay Compression (TRC): A highly efficient method for handling parallel numerical simulation data. Proc. Rom. Acad. 2013, 14, 385-392.

17. Anton, A.A. A method for submodelling inside transient flows. In Proceedings of the 13th International Symposium on Symbolic and Numeric Algorithms for Scientific Computing, Timisoara, Romania, 26-29 September 2011; pp. 75-82.

18. Anton, A.A. Reconstruction of a space-time window in a transient simulation of the breaking of a dam. In Proceedings of the 6th IEEE International Symposium on Applied Computational Intelligence and Informatics (SACI), Timisoara, Romania, 19-21 May 2011; pp. 335-340. 
19. Anton, A.A. Numerical Investigation of Unsteady Flows Using OpenFOAM. Hidraulica 2016, 1, 7-12.

20. Anton, A.A. A new method for reducing the storage requirements of numerical simulation data. In Proceedings of the 2010 International Joint Conference on Computational Cybernetics and Technical Informatics, Timisoara, Romania, 27-29 May 2010; pp. 83-88.

21. Montante, G.; Bakker, A. Solid-Liquid Multiphase Flow Validation in Tall Stirred Vessels with Multiple Impeller Systems, Technical Notes; Fluent Inc.: Lebanon, NH, USA, 2004.

22. Hoseini, S.S.; Najafi, G.; Ghobadian, B.; Akbarzadeh, A.H. Impeller shape-optimization of stirred-tank reactor: CFD and fluid structure interaction analyses. Chem. Eng. J. 2021, 413, 127497. [CrossRef]

23. Valizadeh, K.; Farahbakhsh, S.; Bateni, A.; Zargarian, A.; Davarpanah, A.; Alizadeh, A.; Zarei, M. A parametric study to simulate the non-Newtonian turbulent flow in spiral tubes. Energy Sci. Eng. 2020, 8, 134-149. [CrossRef]

24. De Lamotte, A.; Delafosse, A.; Calvo, S.; Toye, D. Identifying dominant spatial and time characteristics for flow dynamics within free-surface baffled stirred-tanks from CFD simulations. Chem. Eng. Sci. 2018, 192, 12-142. [CrossRef]

25. ANSYS Fluent 16 Help documentation.

26. Stuparu, A.; Susan-Resiga, R.; Tanasa, C. CFD assessment of the hydrodynamic performance of two impellers for a baffled stirred reactor. Appl. Sci. 2021, 11, 4949. [CrossRef]

27. Stuparu, A.; Susan-Resiga, R.; Bosioc, A. Improving the homogenization of the liquid-solid mixture using a tandem of impellers in a baffled industrial reactor. Appl. Sci. 2021, 11, 5492. [CrossRef]

28. Tembely, M.; Alameri, W.S.; AlSumaiti, A.M.; Jouini, M. Pore-scale modelling of the effect of wettability on two-phase flow properties for Newtonian and non-newtonian fluids. Polymers 2020, 12, 22. [CrossRef] [PubMed]

29. Stachnik, M.; Jakubowski, M. Multiphase model of flow and separation phases in a whirlpool: Advanced simulation and phenomena visualization approach. J. Food Eng. 2020, 274, 10. [CrossRef]

30. McCraney, J.; Weislogel, M.; Steen, P. OpenFOAM simulations of late stage container draining in microgravity. Fluids 2020, 5, 16. [CrossRef]

31. Silva, M.F.; Campos, J.B.L.M.; Miranda, J.M.; Araujo, J.D.P. Numerical study of single taylor bubble movement through a microchannel using different CFD packages. Processes 2020, 8, 16. [CrossRef]

32. He, X.; Xu, H.; Li, W.; Sheng, D. An improved VOF-DEM model for soll-water interaction with particle size scaling Comput. Geotehnics 2020, 128, 12.

33. Boffeta, G.; Celani, A.; De Lillo, F.; Musacchio, S. The Eulerian description of dilute collisionless suspension. Europhys. Lett. 2007, 78, 14001. [CrossRef] 